\title{
Struggling with strugglers: using data from selection tools for early identification of medical students at risk of failure
}

\author{
James Li ${ }^{1}$, Rachel Thompson ${ }^{2}$ and Boaz Shulruf ${ }^{2^{*}}$ (D)
}

\begin{abstract}
Background: Struggling medical students is an under-researched in medical education. It is known, however, that early identification is important for effective remediation. The aim of the study was to determine the predictive effect of medical school admission tools regarding whether a student will struggle academically.

Methods: Data comprise 700 students from the University of New South Wales undergraduate medical program. The main outcome of interest was whether these students struggled during this 6-year program; they were classified to be struggling they failed any end-of-phase examination but still graduated from the program. Discriminate Function Analysis (DFA) assessed whether their pre-admission academic achievement, Undergraduate Medicine Admission Test (UMAT) and interview scores had predictive effect regarding likelihood to struggle.

Results: A lower pre-admission academic achievement in the form of Australian Tertiary Admission Rank (ATAR) or Grade Point Average (GPA) were found to be the best positive predictors of whether a student was likely to struggle. Lower UMAT and poorer interview scores were found to have a comparatively much smaller predictive effect.

Conclusion: Although medical admission tests are widely used, medical school rarely use these data for educational purposes. The results of this study suggest admission test data can predict who among the admitted students is likely to struggle in the program. Educationally, this information is invaluable. These results indicate that pre-admission academic achievement can be used to predict which students are likely to struggle in an Australian undergraduate medicine program. Further research into predicting other types of struggling students as well as remediation methods are necessary.
\end{abstract}

Keywords: Medical education, Undergraduate, Australia, Prediction, Medical student

\section{Background}

Research into medical student selection often focuses on prediction models for identifying applicants who would excel as students and less so on those who are likely to fail [1]. However, there is a group of students known as 'strugglers' who fall into neither of these categories. These struggling students are the ones who encounter academic and/or personal difficulties, which causes them to struggle throughout their study in a medical program [1]. Whilst this is a broad categorisation, often the

\footnotetext{
* Correspondence: b.shulruf@unsw.edu.au

${ }^{2}$ Office of Medical Education, University of New South Wales, Sydney,

Australia

Full list of author information is available at the end of the article
}

literature defines such groups differently to one another and uses varying names for the students, such as 'problem learners', 'at-risk students', 'disruptive students', and 'marginal students' [2,3]. The prevalence of strugglers is rarely reported but is believed to lie in the range of 10 $15 \%$ among undergraduate medical programs [2-4], though rates as high as $36.6-47.3 \%$ of students have been reported to have had impeded progress through their medical course [5]. This number could potentially be explained by the usage of different definitions or the fact that struggling students are often unidentified, or poorly reported $[2,6]$. These students often report lower motivation, increased frustration and boredom, and lower confidence in their ability to learn [3, 7]. 
Furthermore, sstruggling has been shown to have a strong association with withdrawal from the course and has also been shown to have significant negative effect upon both the students themselves as well as the universities they attend $[1,3]$.

Currently, the main challenge posed by these struggling students is the need for effective tools and methods to accurately identify them, so that remediation plans can be put in place [7-10]. These students are not necessarily incapable of completing their course, and in fact, it has been suggested that up to $95 \%$ of the struggling medical students do indeed have the essential attributes to successfully complete a medical program [11] . G Paul, G Hinman, S Dottl and J Passon [11] survey, found that students enter medical school with the same level of coping and learning skills, which suggests that struggling students are those who experience more trouble managing their time and the course material. Identifying characteristics specific to students within this group and incorporating them into the medical school selection process could be beneficial as this would allow the implementation of early targeted intervention. Considering the scarcity of knowledge on this topic, research into this area is greatly needed.

The ideal scenario would be to predict those students who may have future difficulties by using data made available through the medical selection process. Previous research suggests that there are a few factors that may be useful for this purpose: lower grades in biology and late offers to the medical program; male gender [12, 13]; lower high school grades [4, 14]; and an inverse relationship between Medical College Admission Test (MCAT) scores and academic difficulty [15]. Some studies reported weak associations between demographic characteristics (e.g. gender, ethnicity etc.) and struggling, but no evidence was found to suggest that factors other than personal attitudes and aptitudes, or previous educational experiences, have any significant impact on the performance of medical students [4].

The group of strugglers is not negligible and too little is known about how best to identify them early in the program. It is therefore suggested that research should be undertaken which aims to: (1) establish a valid set of criteria for identifying struggling students; (2) identify factors that best predict struggling performance; and (3) identify methods for effective intervention. The current study focuses on points $(1,2)$, whereas point (3) should be addressed in future research.

\section{Method}

\section{Setting}

The University of New South Wales (UNSW) is one of the number of medical schools in New South Wales. Ranking for each admission is based on an average of the student's overall UMAT score, structured interview, and GPA or ATAR (which is a measure of pre-admission academic achievement). Predictor (independent) variables were the student scores on these three admission tools (Table 1). The outcome (dependent) variable (Table 1) was derived from whether the student had failed any end-of-phase examination but still graduated from the program, but who had still graduated from the UNSW medical program.

The six-year UNSW undergraduate medicine program has a modular structure comprising fully integrated courses studies over 26 teaching periods, each of 8 weeks duration (Fig. 1). During each of these courses students must sit course examinations. The program is divided in to three phases based on the approach to learning in each phase. Phase 1 consists of eight 8-week courses in years 1 and 2. Phase 2 consists of clinical courses in Year 3 and the Independent Learning Project in Year 4 (students spend this year undertaking a research project). Phase 3 consists of ten clinical placement courses in years 5 and 6 (Fig. 1). To successfully pass through each phase, students must pass through the end-of-phase examinations: an objective structured clinical examination (OSCE), a portfolio examination, and a written examination [16].

\section{Study design}

The present study examines four consecutive cohorts (commencing years 2006-9) of students that have been through and graduated from the UNSW undergraduate medical program in recent years (admissions and assessment outcomes). We established a data set that combined student's admission scores and their examination results by cross-referencing their identification numbers. Each student was categorised as struggling or not struggling; struggling students were defined as any student who failed any end-of-phase examination but still graduated from the program. Only the results of the end-ofphase examinations were used as other examinations throughout the program are mostly modular which means that students might undertake them at different times in their course. In comparison, all the students

Table 1 List of variables

\begin{tabular}{|c|c|}
\hline Predictor Variables & Description \\
\hline UMAT & Mean score across all three UMAT sections \\
\hline $\begin{array}{l}\text { ATAR (or } \\
\text { equivalent) }\end{array}$ & $\begin{array}{l}\text { Measure of prior academic achievement, either from } \\
\text { secondary school (ATAR) or from attendance at a } \\
\text { previous university program (GPA) }\end{array}$ \\
\hline Interview & Total score of their UNSW admission interview \\
\hline \multicolumn{2}{|l|}{ Outcome variable } \\
\hline $\begin{array}{l}\text { Struggling } \\
\text { Status }\end{array}$ & $\begin{array}{l}\text { Whether the student had failed in any of the major } \\
\text { course assessment (described below) whilst still } \\
\text { completing the UNSW medicine program. }\end{array}$ \\
\hline
\end{tabular}




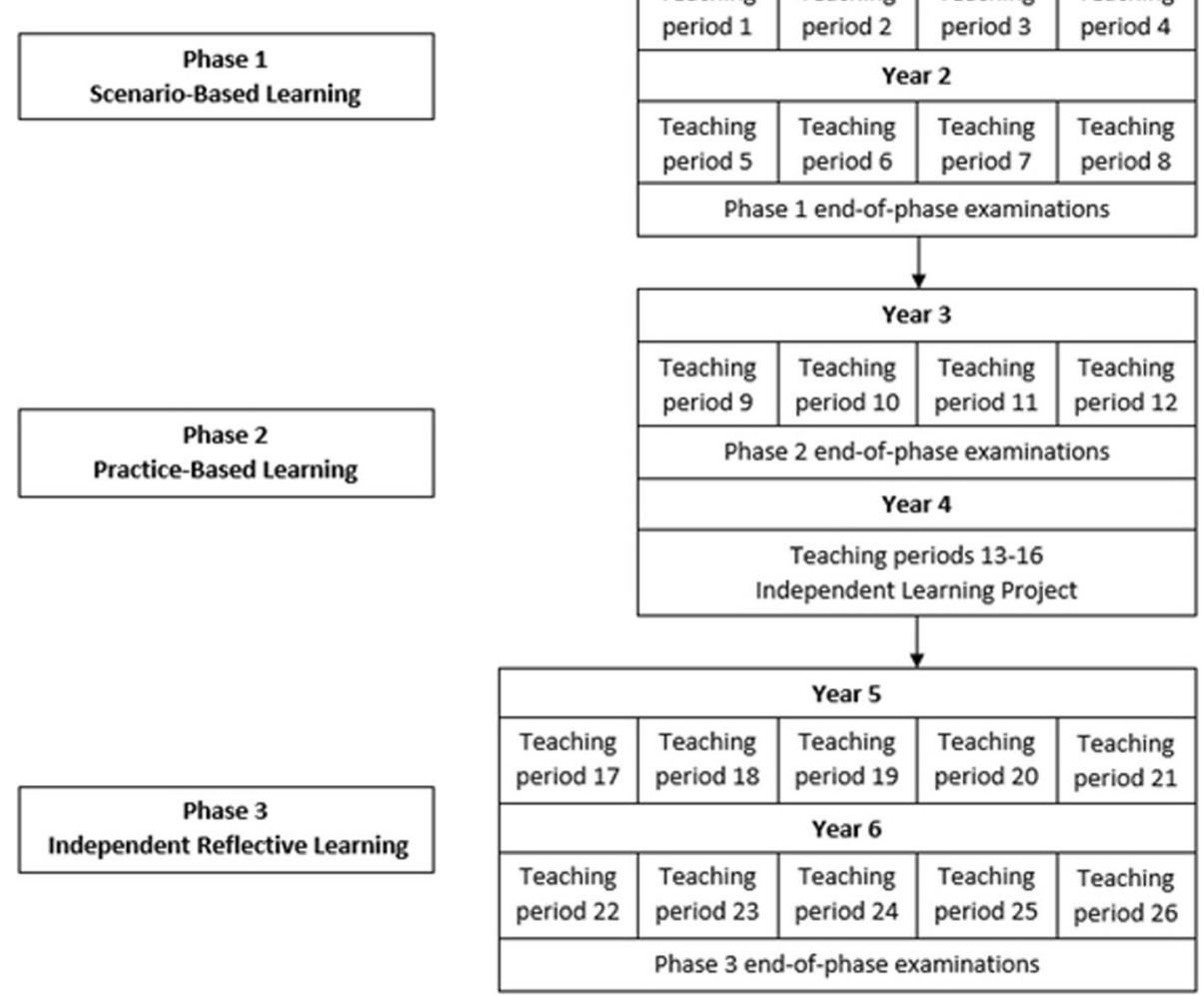

Fig. 1 Structure of the UNSW medical program

must undertake the end-of-phase examinations at the same point in the medicine program which makes these examinations a more fair and direct comparison between the students. Additionally, students can often proceed with the course and resit a failed course examination at a later point whereas they must successfully pass the end-of-phase exams to proceed. All students that failed during the medical program or dropped out prior to completion were excluded from the analysis. Additionally, no students applying through international pathways were included in the analysis as the admission tools used for those students are different in most cases.

\section{Study population}

There were 700 students in our sample of four cohorts that had both admission scores and examination results. The total study population was 700 UNSW undergraduate medical program students of which $55.3 \%$ were female and $44.7 \%$ were male. The 700 were comprised of $77.4 \%$ local and $22.6 \%$ rural students.

\section{Statistical analysis}

We performed a Discriminate function analysis (DFA) to measure how well the current admission tools employed by UNSW were in categorising and differentiating the struggling students from the others. DFA is a statistical procedure that identifies a mathematical function that maximises the accuracy of determining which group a person would belong to, based on the chosen variables [17]. In this study, DFA was used to determine the optimal separation of the students into two groups: a struggling and a not struggling group based on their admission scores. Any student that had to repeat at least one of their end-of-phase assessments or failed an assessment but completed the course was classified as struggling. All other students who graduated from the medicine program without having failed or repeated an end-of-phase assessment were classified as not struggling. The struggling status of the students was compared against their admission scores of ATAR, UMAT and interview scores using the DFA by IBM SPSS v22.0 [18]. The ATAR stands for 'Australian Tertiary Admission Rank' which is a number between 0.00 and 99.95 that indicates a student's position relative to all the students in their age group in NSW in Australia [19]. Applicants/students coming from other states in Australia may have different secondary school results which are then transformed to an ATAR equivalent. UMAT stands for The Undergraduate Medicine and Health Sciences Admission, which is an aptitudes test measuring three 
domains: Logical Reasoning and Problem Solving; Understanding People; and Non-verbal Reasoning [20].

The DFA generates a function that best discriminates between this subgroup of students and the other students.

\section{Ethics approval}

The research was conducted under the ethics approval granted by the Human Research Ethics Committee ofthe University of New South Wales (reference, HC15421, HREAPG: Health, Medical, Community and Social).

\section{Consent}

The ethics approval does not require consent from participants (either for using the data for research or for publication), thus such consent was not obtained. This study used administrative data held UNSW Medicine.

\section{Results}

Of the 700 students, 35 were defined to be 'struggling' or have struggled during their degree program. Based on the results of the DFA (Table 2), with $73.7 \%$ of the cases being correctly classified we proceeded to examine the unstandardized discrimination function coefficients. Based on these results, all three of the admission tools we were investigating were found to negatively predict 'strugglers'. The use of the three admission tools in predicting which students are likely to struggle produced an odds ratio of $2.05,(95 \%$ CI $1.02-4.13, p=0.044)$. When comparing the standardised function coefficients (Table 3), ATAR had the greatest impact in predicting which students were likely to struggle: the lower the ATAR, the greater the likelihood of the student struggling. The ATAR was found to have a 3-4 times greater impact in predicting who is likely to struggle in comparison to UMAT and interview scores.

The mathematical function produced by the DFA is summarised by the Canonical Discriminate Function Coefficients and the Group centroids (Table 3). Using the corresponding coefficients for each admission factor the optimal cut-score can be produced. Since struggling is a negative value whereas not-struggling is a positive value, any student that falls above the cut-score determined by

Table 2 DFA summary table

\begin{tabular}{|c|c|c|c|c|c|}
\hline \multicolumn{6}{|c|}{ Classification Results $^{\mathrm{a}}$} \\
\hline & & \multirow[b]{2}{*}{ Struggling Status } & \multicolumn{3}{|c|}{ Predicted Group Membership } \\
\hline & & & 0 & 1 & Total \\
\hline \multirow[t]{4}{*}{ Original } & Count & Not Struggling & 502 & 163 & 665 \\
\hline & & Struggling & 21 & 14 & 35 \\
\hline & $\%$ & Not Struggling & 75.5 & 24.5 & 100.0 \\
\hline & & Struggling & 60.0 & 40.0 & 100.0 \\
\hline
\end{tabular}

${ }^{\mathrm{a}} 73.7 \%$ of original grouped cases correctly classified
Table 3 Efficacy of selection tools in predicting students likely to struggle

\begin{tabular}{lll}
\hline Canonical Discriminate Function & Standardised & Unstandardised \\
Coefficients & & \\
\hline ATAR (or Equivalent) & 0.931 & 0.570 \\
UMAT & 0.219 & 0.040 \\
Interview & 0.297 & 0.028 \\
(Constant) & & -61.110 \\
Functions at Group Centroids & & \\
Struggling Status & & \\
$\quad$ Not Struggling & 0.015 & \\
$\quad$ Struggling & -0.290 & \\
\hline
\end{tabular}

the DFA would be most likely to be not struggling compared to any student that is below the cut-score. The standardised values allow a comparison of the predictive effect of each admission factor and this shows that ATAR (or equivalent) has the greatest predictive effect of struggling students out of the three admission tools that were analysed.

\section{Discussion}

This study focused on an overlooked, yet important topic in medical student admissions, while determining whether or not selection tools (ATAR, UMAT, and interview scores) had any utility in identifying which students would most likely struggle during an Australian undergraduate medical program. We found that all three admission scores had a slight association, but that the ATAR had the strongest inverse association out of the three admission tools in differentiating struggling students from the other students.

\section{Comparison to other studies}

This study is both novel in the target population we examined as well as in the techniques utilized. Most studies in this area primarily focus on the use of admission tools in identifying students that are most likely to perform well at university, or in identifying those that are likely to fail $[21,22]$. This study differs by focusing upon the lesser-researched population of 'struggling' students $[21,22]$. For the purposes of this study, the focus was on students who struggle academically; defined as any student that successfully graduated from the program but had encountered issues with the course (e.g. failing one or more exams) (see: Method section). The second novel aspect of this project was in the use of DFA for exploring the effectiveness of current medical school selection tools [23].

Other current research regarding admission tools and medical school performance are generally focused on students that excel and students that fail as opposed to looking at the struggling students in between. The 
consensus of these studies as well as the few that have looked at struggling students is that pre-admission ATAR/GPA is the most effective tool in predicting student performance in the medical program [5, 24-27]. This is often assumed to be the case as ATAR/GPA may be a reflection of either an initial shortcoming in biological concepts and processes, or a shortcoming in their academic ability such as their study skills [28].

\section{Future policy and research}

Our findings raise two main points with respect to the use of these admission tools in admitting students. Firstly, our findings agree with the consensus that previous academic achievement (comprised of either ATAR or GPA) seems to be the most effective admission tool in helping to determine which students should be admitted, but this does question the use of the interview and UMAT with equal weighting to a student's ATAR or GPA [5, 29]. This is because the other two admission tools have a substantially lower predictive effect than that of the ATAR, though perhaps those two tools are useful in identifying other characteristics that the university finds desirable in its students [16].

The other issue that our findings raise is that the ability of these admission tools to classify these students is neither ineffective nor infallible, but somewhere in between. One question we must consider is whether we can truly say that we can linearly rank/model these students, with the students that do best on the upper end of the scale and the students that fail on the lower end of the scale. Whilst the consensus is that previous academic achievement in the form of ATAR/GPA is the most consistent predictor of medical program success [29], the results of this study suggest that it is not perfect. In that regard, there is the possibility for improvement in terms of admission tools which may allow better ability to identify students that will struggle as well as in creating a more diverse and desirable range of students.

In terms of how these findings could be applied to the medical education and medical programs at various universities, the most straightforward and potentially beneficial way would be to assist struggling students early to prevent future struggling throughout their time in the medical program [9]. Currently, universities can only provide support once a student has already been shown to be struggling (e.g. failing an exam) but based on our results universities could offer targeted support to the specific students who are likely to struggle. This is in comparison to the current situation where, if universities wanted to offer early support, it would realistically have to be broad support to the entire student population. By using our findings in this way universities could assist students prior to them struggling and prevent these students from suffering the negative consequences of struggling.

Even though our results show that ATAR/GPA can be used reasonably reliably to identify struggling students, more research needs to be done intotheeffective longterm remediation to assist these students. Additionally, research delving in to the benefits of the use of the UMAT and interviews as admission tools may prove useful as they may in fact be more predictive of other desirable qualities and thus may lead to greater diversity in the medical student and doctor population [25].

\section{Limitations}

The limitations of our study were primarily based on the data we had access to. We were only able to investigate struggling students that had failed in one of the end of phase assessments (as mentioned previously) based on the assessment results we had access to. Because a struggling student was defined as one who failed or had to repeat any end-of-phase assessment but still completed the medicine program, other types of struggling students may have been missed in the scope of this study. Other studies have identified different types of struggling students such as those that may have to postpone or failed assessment because of illness [28] . Additionally, since this study was focused upon the three main admission tools of UMAT, ATAR/GPA and interview scores, many international students who were admitted without the use of all three of these tools were unable to be included within our study. Being unable to assess all possible different categories of struggling students was unavoidable for our project as we were using previously acquired data. For further research, more detailed data and analysis regarding different types of struggling students may provide greater insight in to the predictability of the current admission tools overall.

\section{Conclusions}

The results of this study show that ATAR/GPA is effective in predicting which students are likely to be struggling within the UNSW medical program. Results of this study could be used by other medical schools to assist in early identification of students that are likely to struggle. This would in turn allow the faculty to monitor, track, support, and remediate the students during their time in the medical program. Doing so early is likely to result in better outcomes for these students as well as better prepared and well-equipped physicians entering the medical workforce.

\section{Abbreviations}

(GPA): UNSW: University of New South Wales; ATAR: AustralianTertiary Admission Rank; GPA: Grade Point Average; UMAT: The Undergraduate Medicine and Health Sciences Admission Test 


\section{Acknowledgements}

The authors express their gratitude to the UMAT consortium for their support of this research.

\section{Authors' contributions}

BS has initiated the study, designed the methodology, supervised the conduct of the study, interpret the results and contributed to the writing. JL undertook the data management and analysis contributed to the interpretation of the results and to the writing of the manuscript. RT contributed to the interpretation of the results and to the writing of the manuscript. All authors read and approved the final manuscript.

\section{Funding}

This study was funded by a grant awarded from the UMAT Consortium. The UMAT consortium had no role inthe design of the study, data collection, data analysis and interpretation, orin writing the manuscript.

\section{Availability of data and materials}

Data may be available by request submitted to the corresponding author, subject to the approval the Human Research Ethics Committee ofthe University of New South Wales.

\section{Ethics approval and consent to participate}

The research was conducted under the ethics approval granted by the Human Research Ethics Committee ofthe University of New South Wales (reference, HC15421, HREAPG: Health, Medical, Community and Social).

\section{Consent for publication}

The ethics approval does not require consent from participants (either for using the data for research or for publication), thus such consent was not obtained. This study used administrative data held by UNSW Medicine.

\section{Competing interests}

The authors report no conflicts of interest. The authors alone are responsible for the content and writing of this article. Author Boaz Shulruf is a member of the editorial board for BMC Medical Education. He had no editorial role in the processing or peer review of this manuscript and was blinded to this process.

\section{Author details}

${ }^{1}$ Faculty of Medicine, University of New South Wales, Sydney, Australia. ${ }^{2}$ Office of Medical Education, University of New South Wales, Sydney, Australia.

Received: 14 May 2019 Accepted: 29 October 2019 Published online: 09 November 2019

\section{References}

1. Yates J, James D. Predicting the "strugglers": a case-control study of students at Nottingham University medical school. BMJ. 2006; 332(7548):1009-13.

2. Frellsen S, Baker E, Papp K, Durning S. Medical school policies regarding struggling medical students during the internal medicine clerkships: results of a National Survey. Acad Med. 2008;83(9):876-81.

3. O'Neill L, Morcke A, Eika B. The validity of student tutors' judgments in early detection of struggling in medical school. A prospective cohort study. Adv Health Sci Educ. 2016;21(5):1061-79.

4. Yates J, James D. Risk factors for poor performance on the undergraduate medical course: cohort study at Nottingham University. Med Educ. 2007;41:65-73.

5. Sladek R, Bond M, Frost L, Prior K. Predicting success in medical school: A longitudinal study of common Australian student selection tools. BMC Medical Education. 2016:16(1).

6. Cleland J, Knight L, Rees C, Tracey S, Bond C. Is it me or is it them? Factors that influence the passing of underperforming students. Med Educ. 2008; 42(8):800-9.

7. Artino ARJ, Hemmer PA, Durning SJ. Using self-regulated learning theory to understand the beliefs, emotions, and behaviors of struggling medical students. Acad Med. 2011;86(10):S35-8.
8. Papadakis M, Teherani A, Banach M, Knettler T, Rattner S, Stern D, Veloski J, Hodgson C. Disciplinary action by medical boards and prior behavior in medical school. N Engl J Med. 2005;353(25):2673-82.

9. Ford M, Masterton G, Cameron H, Kristmundsdottir F. Supporting struggling medical students. Clin Teach. 2008;5(4):232-8.

10. Steinert Y. The "problem" learner: whose problem is it? AMEE guide no. 76. Medical Teacher. 2013;35(4):e1035-45.

11. Paul G, Hinman G, Dottl S, Passon J. Academic development: a survey of academic difficulties experienced by medical students and support services provided. Teaching and Learning in Medicine. 2009;21(3):254-60.

12. Yates J, James D. Risk factors at medical school for subsequent professional misconduct: multicentre retrospective case-control study. BMJ. 2010;340.

13. Shulruf B, Hattie J, Tumen S. Individual and school factors affecting Students' participation and success in higher education. High Educ. 2008; 56(5):613-32.

14. Shulruf B, Shaw J. How the admission criteria to a competitive-entry undergraduate programme could be improved. High Educ Res Dev. 2014:1-14.

15. Julian E. Validity of the medical college admission test for predicting medical school performance. Acad Med. 2005;80(10):910-7.

16. McNeil P, Hughes C, Toohey S, Dowton S. An innovative outcomes-based medical education program built on adult learning principles. Medical Teacher. 2006;28(6):527-34.

17. Garson D. Discriminant function analysis. Asheboro: Statistical Associates Publishing; 2012.

18. IBM.: IBM SPSS Statistics 22 Command Syntax Reference: IBM Corp.; 2013.

19. What is the ATAR? [https://www.uac.edu.au/future-applicants/atar].

20. Australian Council for Educational Research: UMAT 2018. Melbourne, Australia: Australian Council for Educational Research; 2018.

21. O'Neill L, Hartvigsen J, Wallstedt B, Korsholm L, Eika B. Medical school dropout - testing at admission versus selection by highest grades as predictors. Med Educ. 2011:45(11):1111-20.

22. O'Neill L, Wallstedt B, Eika B, Hartvigsen J. Factors associated with dropout in medical education: a literature review. Med Educ. 2011;45(5):440-54.

23. Kreiter C, Solow C. A statistical technique for the development of an alternate list when using constrained optimization to make admission decisions. Teaching and Learning in Medicine. 2002;14(1):29-33.

24. Shulruf B, Bagg W, Begun M, Hay M, Lichtwark I, Warnecke E, Wilkinson T, Poole P. Efficacy of medical student selection tools in Australia and New Zealand. Med J Aust. 2018;208(5):214-8.

25. Poole P, Shulruf B, Rudland J, Wilkinson T. Comparison of UMAT and admission GPA on the prediction of performance on medical school assessments: a national, cross-institution study. Med Educ. 2012;46:163-71.

26. Kim T, Chang JY, Myung SJ, Chang Y, Park KD, Park WB, Shin CS. Predictors of undergraduate and postgraduate clinical performance: a longitudinal cohort study. Journal of Surgical Education. 2016;73(4):715-20.

27. Salem R, Al-Mously N, AlFadil S, Baalash A: Pre-admission criteria and preclinical achievement: Can they predict medical students performance in the clinical phase? Medical Teacher 2016, 38(sup1):S26-S30.

28. Garrud $P$, Yates J. Profiling strugglers in a graduate-entry medicine course at Nottingham: a retrospective case study. BMC Medical Education. 2012;12(1):124.

29. Mercer A, Puddey I. Admission selection criteria as predictors of outcomes in an undergraduate medical course: a prospective study. Medical Teacher. 2011;33:1-8.

\section{Publisher's Note}

Springer Nature remains neutral with regard to jurisdictional claims in published maps and institutional affiliations. 